\title{
Comparative analysis of cyanobacterial superoxide dismutases to discriminate canonical forms
}

\author{
Balakrishnan Priya ${ }^{\dagger 1}$, Jagadeesan Premanandh ${ }^{\dagger 1}$, Raman T Dhanalakshmi ${ }^{1}$, \\ Thangaraj Seethalakshmi ${ }^{2}$, Lakshmanan Uma1, Dharmar Prabaharan*1 and \\ Gopalakrishnan Subramanian ${ }^{1}$
}

\author{
Address: ${ }^{1}$ National Facility for Marine Cyanobacteria (Sponsored by Department of Biotechnology, Government of India), Bharathidasan \\ University, Tiruchirappalli - 620 024, India and ${ }^{2}$ School of Physics, Bharathidasan University, Tiruchirappalli - 620 024, India \\ Email: Balakrishnan Priya - priyamic@yahoo.com; Jagadeesan Premanandh - jpanandh@yahoo.com; \\ Raman T Dhanalakshmi - dhanam_biobdu@rediffmail.com; Thangaraj Seethalakshmi - seetha_b2002@yahoo.com; \\ Lakshmanan Uma - uma_nfmc@yahoo.com; Dharmar Prabaharan* - pub_nfmc@yahoo.co.in; Gopalakrishnan Subramanian - gsjaya@eth.net \\ * Corresponding author †Equal contributors
}

Published: 27 November 2007

BMC Genomics 2007, 8:435 doi:10.1|86/|47|-2164-8-435
Received: 8 May 2007

Accepted: 27 November 2007

This article is available from: http://www.biomedcentral.com/I47I-2/64/8/435

(c) 2007 Priya et al; licensee BioMed Central Ltd.

This is an Open Access article distributed under the terms of the Creative Commons Attribution License (http://creativecommons.org/licenses/by/2.0), which permits unrestricted use, distribution, and reproduction in any medium, provided the original work is properly cited.

\begin{abstract}
Background: Superoxide dismutases (SOD) are ubiquitous metalloenzymes that catalyze the disproportion of superoxide to peroxide and molecular oxygen through alternate oxidation and reduction of their metal ions. In general, SODs are classified into four forms by their catalytic metals namely; FeSOD, MnSOD, Cu/ZnSOD and NiSOD. In addition, a cambialistic form that uses Fe/Mn in its active site also exists. Cyanobacteria, the oxygen evolving photosynthetic prokaryotes, produce reactive oxygen species that can damage cellular components leading to cell death. Thus, the co-evolution of an antioxidant system was necessary for the survival of photosynthetic organisms with SOD as the initial enzyme evolved to alleviate the toxic effect. Cyanobacteria represent the first oxygenic photoautotrophs and their SOD sequences available in the databases lack clear annotation. Hence, the present study focuses on structure and sequence pattern of subsets of cyanobacterial superoxide dismutases.
\end{abstract}

Result: The sequence conservation and structural analysis of Fe (Thermosynechococcus elongatus BPI) and MnSOD (Anabaena sp. PCC7I20) reveal the sharing of $N$ and $C$ terminal domains. At the $C$ terminal domain, the metal binding motif in cyanoprokaryotes is DVWEHAYY while it is D-X-[WF]-E-H-[STA]-[FY]-[FY] in other pro- and eukaryotes. The cyanobacterial FeSOD differs from MnSOD at least in three ways viz. (i) FeSOD has a metal

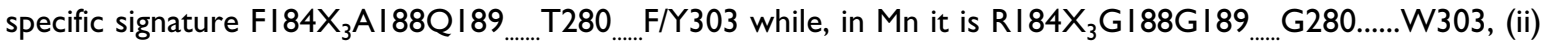
aspartate ligand forms a hydrogen bond from the active site with the outer sphere residue of W243 in Fe where as it is Q262 in MnSOD; and (iii) two unique lysine residues at positions 201 and 255 with a photosynthetic role, found only in FeSOD. Further, most of the cyanobacterial Mn metalloforms have a specific transmembrane hydrophobic pocket that distinguishes FeSOD from $\mathrm{Mn}$ isoform. Cyanobacterial $\mathrm{Cu} / \mathrm{ZnSOD}$ has a copper domain and two different signatures G-F-H-[ILV]-H-x-[NGT]-[GPDA]-[SQK]-C and G-[GA]-G-G-[AEG]-R-[FIL]-[AG]$\mathrm{C}-\mathrm{G}$, while $\mathrm{Ni}$ isoform has an nickel containing SOD domain containing a Ni-hook HCDGPCVYDPA.

Conclusion: The present analysis unravels the ambiguity among cyanobacterial SOD isoforms. NiSOD is the only SOD found in lower forms; whereas, Fe and $\mathrm{Mn}$ occupy the higher orders of cyanobacteria. In conclusion, cyanobacteria harbor either $\mathrm{Ni}$ alone or a combination of $\mathrm{Fe}$ and $\mathrm{Ni}$ or Fe and $\mathrm{Mn}$ as their catalytic active metal while $\mathrm{Cu} / \mathrm{Zn}$ is rare. 


\section{Background}

Superoxide dismutases (SODs, E.C. 1.15.1.1) are the superfamily of metalloenzymes that dismutases the highly toxic and reactive superoxide radical $\left(\mathrm{O}_{2}-\right.$, by-product of aerobic metabolism) through a cyclic oxidationreduction ('ping-pong') mechanism. As described by McCord and Fridovich [1], it is the first line of defense to alleviate oxidative stress virtually in all living organisms that survive in oxic environment.

The evolutionary trajectory has favored SOD as a ubiquitous enzyme in multiple forms within a single organism or cell, indicating a fail-safe redundancy that emphasizes the importance of this family of enzymes against reactive oxygen species (ROS). Based on metal cofactors, four known (canonical) isoforms viz., iron (Fe), manganese $(\mathrm{Mn})$, copper/zinc $(\mathrm{Cu} / \mathrm{Zn})$ and nickel $(\mathrm{Ni})$ SODs have been identified. In general, SODs have a strict metal binding specificity for enzymatic activities with the exception of a class of enzymes which show enzymatic activity regardless of whether Fe or $\mathrm{Mn}$ is bound at the active site; these are known as cambialistic forms [2-5].

Cyanoprokaryotes are oxygen evolving photosynthetic organisms occupying a crucial position between pro- and eukaryotes. They are considered to be primeval having evolved about 3.2 billion years ago [6]. In addition, they succeeded in linking photosynthetic electron flow from water as the photoreductant through an oxygen-evolving complex at the high-potential side of the newly elaborated photosystem II, which is thought to have originated from a uniform primordial photosystem by gene duplication [7]. The resultant tandem operation of two photosystems is now known as oxygenic or plant-type photosynthesis [8]. This marked the turning point in the evolution of earth, opening up the era of an aerobic, oxygen-containing biosphere and SOD is found to play a critical role in mitigating the toxic effect of superoxide ion. The first implication on the protective role of cyanobacterial SOD in photo-oxidative damage was shown in Anacystis nidulans [9]. Subsequently, several studies on protective role of SODs of cyanobacteria in response to various physiological processes/stresses like photosynthesis [10], desiccation $[11,12]$, chilling [13], nitrogen starvation [14] and with azo dyes (unpublished) have been reported.

Metal preferences in Fe and MnSODs have been well documented in both pro- and eukaryotic forms [15-17]. However, no information is available on distinguishing the canonical isoforms of cyanobacteria. Hence, the present study focuses on structure and sequence pattern of subsets of cyanobacterial SODs to explore the possibility of solving the ambiguity.

\section{Results and Discussion}

For the survival of cyanobacteria with oxygenic photosynthesis, the selection pressure led to the evolution of SODs as the first antioxidant arsenal against nascent oxygen species. Studies on cyanobacterial SODs would serve as a window into the past and present evolutionary events of these primitive phototrophs.

On comparison, the canonical isoforms of SOD, Fe and MnSOD's are structurally distinct from $\mathrm{Cu} / \mathrm{Zn}$ and NiSOD. Both Fe and MnSOD are typically homodimers or tetramers (Fig 1A,C) sharing identical metal chelating residues at the active site with a high degree of sequence and structural homology except for slight differences in amino acid residues. For instance, the amino acid range in cyanobacterial FeSOD is 199-229 residues with a molecular weight of 21-25 KDa, whereas in MnSOD, it is 200-316 amino acids with a molecular weight of 22-34 KDa.

Both SODs revealed a common topology with all $\alpha$ N-terminal (Pfam:PF00081) and a $\alpha / \beta$ C terminal domains (Pfam:PF02777) (Fig 1B,D). The sequence pattern for Fe and MnSODs of eukaryotes and other non-cyanobacterial prokaryotes is D-X-[WF]-E-H-[STA]-[FY]-[FY] [18];

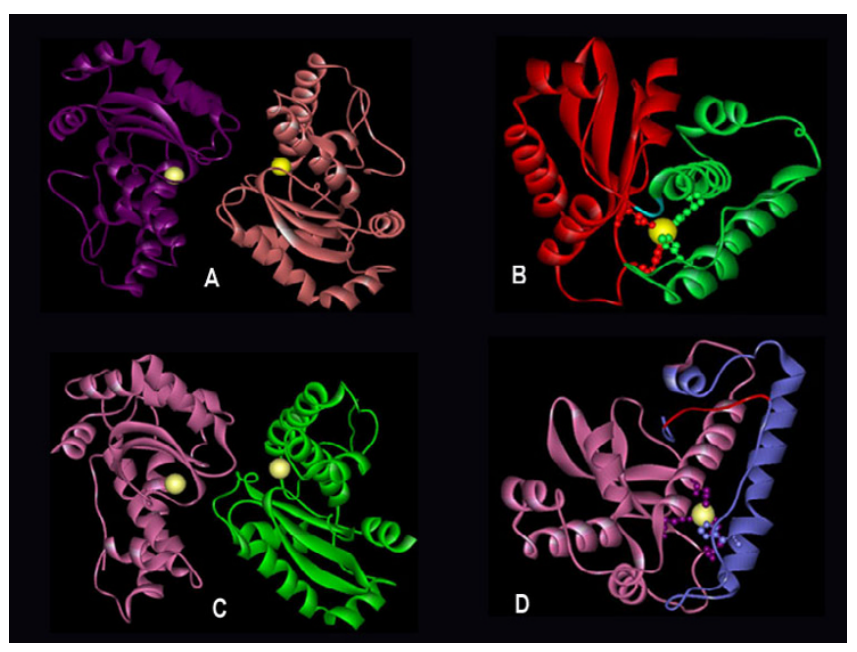

Figure I

Structure of Fe and MnSOD. Structures are visualized using WebLab ViewerLite 4.2 software. Catalytically essential aspartate or histidine residues are represented in ball and stick mode binding the active metal (yellow) is shown to identify the location of the active site. Protein database codes are given in parentheses: (i) FeSOD (PDB Igv3); (ii) MnSOD (PDB Imy6). (A) FeSOD of T.elongatus BP-I dimers are distinguished by colour (violet and slate), and structures are represented with the active site (yellow) of subunit. (B) Monomeric subunit of FeSOD represents an $\mathrm{N}$ terminal (green) and a C- terminal (red). Similarly (C) represents dimer structure of Anabaena sp. MnSOD in pink and green with active site highlighted in yellow. (D) Monomeric MnSOD showing the $\mathrm{N}$-terminal residues in blue and $\mathrm{C}$-terminal in pink with metal binding ligands. The transmembrane hydrophobic pocket specific for MnSOD is highlighted in red (D). 
whereas, the analysis of the sequence conservation in cyanobacteria (based on available data) showed a specific motif DVWEHAYY [D282-Y289, based on Fig 2]. This motif extends between the second $\alpha$-helix and the first $\beta$ sheet of the C-terminal domain in both the SOD's. The highly conserved residues aspartate D282 and histidine $\mathrm{H} 286$, a constituent of the motif are the metal binding ligands. In addition, glutamic acid E285 and tyrosine Y289 form a dimer surface spanning the interface and bridging the active sites between the opposite halves of each subunit, see Figure 2 (For full image, please see Additional file $1)$.

Structural analysis of available cyanobacterial $\mathrm{Fe}$ and MnSODs, confirms that both share a similar active site (i.e., metal ion) being coordinated in the respective isoform by three histidine and an aspartate residue with a ligating solvent molecule (water or $\mathrm{OH}$ ), a five coordinated trigonal bipyramidal geometry. In Thermosynechococcus elongatus (PDB code 1my6); the $\mathrm{Fe}$ ion is coordinated by the carboxylate oxygen (O82) of D161 with the amino group (Nع2) of H79, 27, 165 along with the oxygen atom of the water molecule. The hydrogen bonding distance between $\mathrm{O} \delta 2$ (D161) and N\&2 (H27 and H79) is $2.79 \AA$ and $3.27 \AA$ respectively (Table 1 ). In case of Anabaena sp (PDB code: 1gv3), the Mn is coordinated by NE2 of H117, 204, 62 and O 82 of D200. The hydrogen bonding between O 22 (D200) and Ne2 (H62 and H117) is $2.19 \AA$ and $3.33 \AA$ respectively. These hydrogen bonds are involved in stabilizing the orientation of the ligand residues in MnSOD [8]. The observed contact surface area (31-35 $\left.\AA^{2}\right)$ between the side chain aspartate

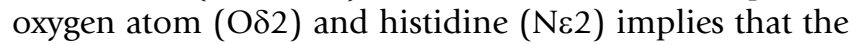

metal coordination ligands in the exposed region may perhaps tune the redox potential (Fig 3, 4).

The motif and metal binding sites of $\mathrm{Fe}$ and $\mathrm{Mn}$ isoforms appear to exhibit similar function. However, the sequence alignment and structural analysis reveal their possible discrimination by three traits to specifically differentiate $\mathrm{Fe}$ and $\mathrm{Mn}$ isoforms (Table 1 Additional file 1).

First, is the change in conserved amino acid signature

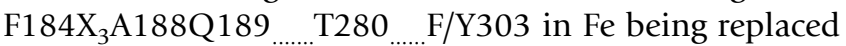

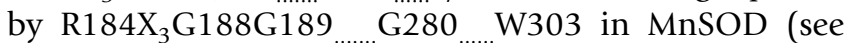
Figures 2 and 5).

The second notable feature is related to the metal bound solvent molecule that serves as a hydrogen bond to the non-coordinated oxygen of the carbonyl group of the aspartate ligand accepting a hydrogen bond from an outer sphere residue [19]. In MnSOD, it is glutamine Q262 (Fig 2 ) arising from the end of the $\beta_{2}$-strand and $\mathrm{H}_{9}$ in the $\mathrm{C}$ terminal domain, while in FeSOD, it is tryptophan W243 arising from the middle of the sequence (within the $\beta_{1}$ ) in the C-terminal domain. In the case of cambialistic $\mathrm{Fe} /$ MnSOD metalloform reported in archaea (Pyrobaculum aerophilum ) [19], the outer-sphere H-bonding residue is histidine. This residue plays a major role in altering the solvent interaction with the active site metal ion in cambialistic Fe/Mn SOD isoform [19]. The sequence analysis of cyanobacterial SODs showed the absence of this histidine residue which probably suggests the absence of cambialistic forms in cyanobacteria. Vance and Miller [20] reported that the most highly conserved residues glutamine Q262 in Mn and Q189 of FeSOD forms the outer sphere hydro-

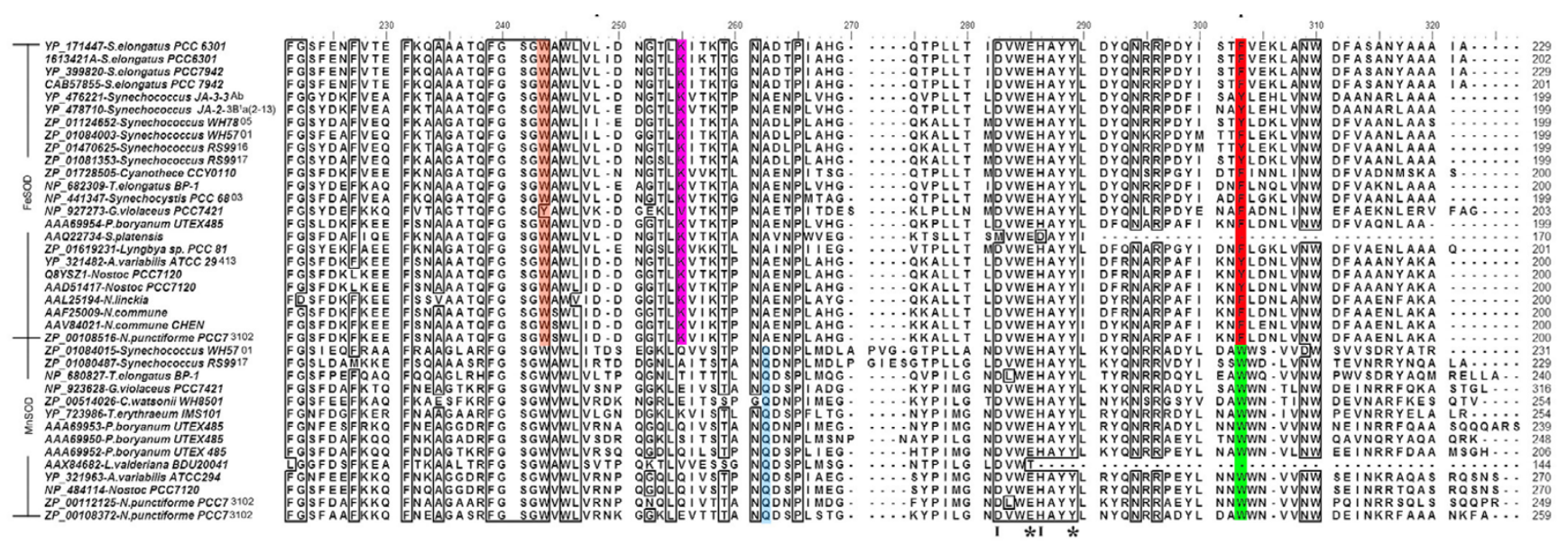

\section{Figure 2}

This figure shows the lower quartile of protein sequence alignment of Fe and MnSODs in cyanobacteria. The highly conserved metal specific residues are highlighted in red for Fe and green for MnSODs. Residues involved in outer sphere hydrogen bonding for $\mathrm{Mn}$ is highlighted in cyan and for Fe in orange. For FeSOD, the lysine residues involved in photosynthetic context is shown in pink. The active site residues are marked as $\mathbf{I}$ and the dimer residues are represented by $\star$. 


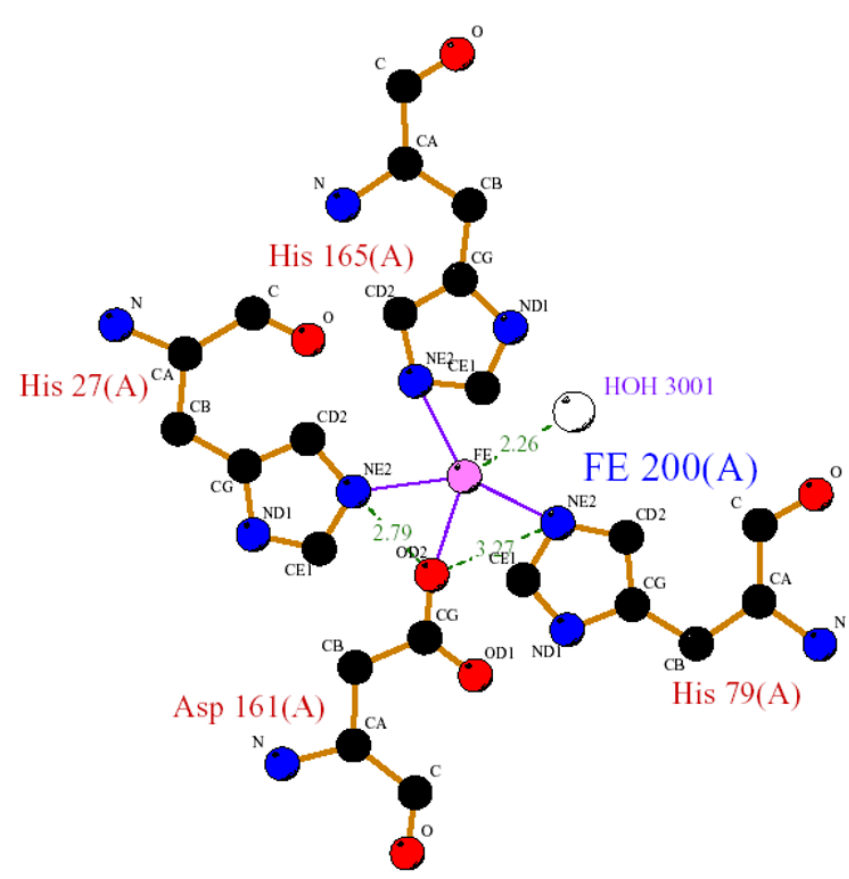

Figure 3

The active site residues of Fe Superoxide dismutase of Thermosynechococcus elonagtus.

gen-bond network exerts a large influence on redox midpoint potential tuning for catalytic activity of SOD's.

The third difference is the presence of two lysine residues, K201 and 255 in FeSOD but not in MnSOD (Fig 2 and 5). These residues seem to be unique and function specific to cyanobacteria among prokaryotes [21]. K201 lines a small pit at the surface of the T. elongatus and of higher plants FeSOD, formed by the loop P202-G203-G204 connecting $\mathrm{N}$ and $\mathrm{C}$ terminal domains. Likewise, K255 is restricted only to cyanobacteria, indicating its importance in the photosynthetic context [21].

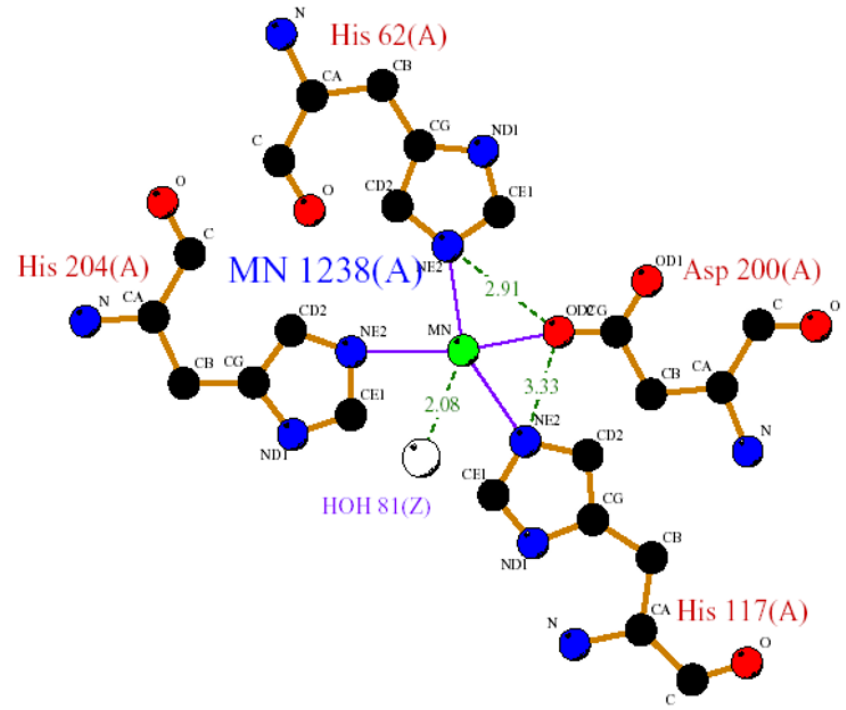

Figure 4

The active site residues of $\mathrm{Mn}$ Superoxide dismutase of Anabaena sp.

Cyanobacterial MnSOD is the only SOD to be membrane anchored by transmembrane helix [22]. The factor that determines localization of MnSOD is found to span the $\mathrm{N}$ terminal which is a hydrophobic transmembrane helix (Fig 1D, 6). The cyanobacterial representatives such as (Synechococcus sp. WH5701 (EAQ76095), Synechococcus sp. RS9917 (EAQ68777), Trichodesmium erythraeum IMS101 (EAO27349), Anabaena variabilis ATCC29413 (ABA21068) and Nostoc sp. PCC7120 (BAB77594)) clearly corroborate this (Fig 6).

Cyanobacterial $\mathrm{Cu} / \mathrm{ZnSOD}$ isoform bears no resemblance to $\mathrm{Fe}$ or $\mathrm{Mn}$ or $\mathrm{Ni}$ isoform in relation to its primary and tertiary structure. The theoretical molecular weight ranges between 16-23 KDa with an amino acid length of 174-233 residues. Further, study on amino acid composition illustrates that it is rich in Gly $(11-16 \%)$ forming eight $\beta$-sheets (Fig 7A) accredited to be involved in confor-

Table I: Discriminatory key to classify indecisive isoforms.

\begin{tabular}{|c|c|c|}
\hline Characteristics & FeSOD & MnSOD \\
\hline Metal specificity & $\mathrm{Fe}$ & Mn \\
\hline Amino acid length & $199-229$ & $200-316$ \\
\hline Theoretical molecular weight & $2 \mathrm{I}-25 \mathrm{KDa}$ & $22-34 \mathrm{KDa}$ \\
\hline No. of a helix* & 13 & 14 \\
\hline No. of b strand* & 3 & 3 \\
\hline Domains & $N \& C$ terminal & $N \& C$ terminal \\
\hline Motif & DVWEHAYY & DVWEHAYY \\
\hline Active site residues* & Fig 3 & Fig 4 \\
\hline Structurally highly conserved metal specific residues & 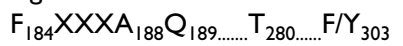 & $R_{184} X X X G_{188} G_{189 \ldots \ldots . .} G_{280 \ldots \ldots . .} W_{303}$ \\
\hline Conserved residue with photosynthetic role & $\mathrm{K} 87, \mathrm{KI} 39$ & None \\
\hline Transmembrane hydrophobic pocket & Absent & Present \\
\hline
\end{tabular}

* - Based on the structural analysis of MnSOD of Anabaena sp. (PDB No: Igv3) and FeSOD of Thermosynechococcus elongatus BP-I (PDB No: Imy6) 

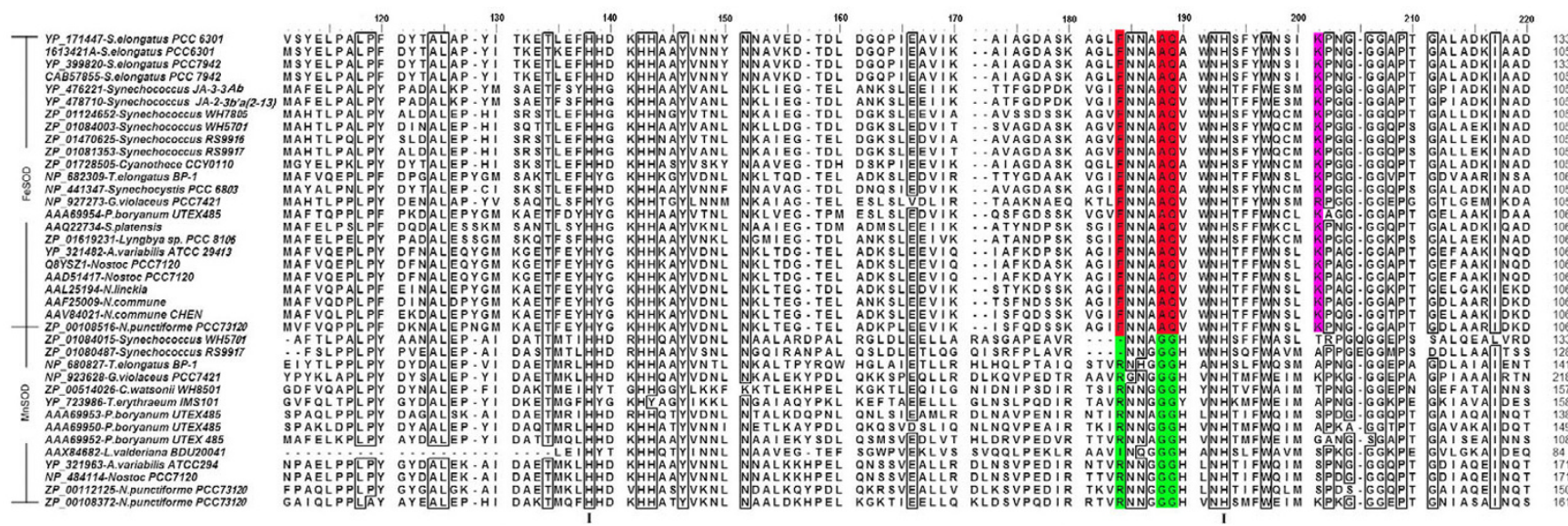

\section{Figure 5}

This figure shows the second quartile of protein sequence alignment of Fe and MnSODs in cyanobacteria. For full image, please see Additional file I. The conserved aminoacid signature for Fe and MnSODs are highlighted in red and green respectively. Lysine residues of FeSOD involved in photosynthetic context is depicted in pink. The active site residues are labeled as $\mathbf{I}$.

mation [23] and stability in repeated freeze/thaw cycles and prolonged refrigeration [9]. These isoforms in general have a copper containing domain (Pfam:PF00080) with two different signatures. The first is G-F-H-[ILV]-H-x[NGT]-[GPDA]-[SQK]-C where the conserved histidine is involved in copper binding, and the second being G-[GA]G-G-[AEG]-R-[FIL]-[AG]-C-G where $\mathrm{C}$ is involved in disulfide bonding (Fig 8). G. violaceus SOD (NP_925116, NP_924927) annotated as 'similar to SOD' contains only copper binding domain and both the signatures are absent. Further confirmation requires additional structural data. Each monomer is comprised of a binuclear metal centre with one $\mathrm{Cu}$ and one $\mathrm{Zn}$ atom. The noticeable $\beta$ parallel fold of cyanobacterial $\mathrm{Cu} / \mathrm{Zn}$ isoform mimics the structure of Salmonella typhimurium $\mathrm{Cu} / \mathrm{ZnSOD}$ [24] (Fig 7B). The catalytic coordination sphere of $\mathrm{Cu}^{2+}$ ion is by $\mathrm{N} \delta 1$ of H103, Nع2 of H105, H147 and H215 and $\mathrm{Zn}^{2+}$ by $\mathrm{N} \delta 1$ of three H147, 157, 171 and $\mathrm{O} \delta 1$ of one D174 (Fig 8). Besides this, structural comparison designates the two specific hydrogen bonds between the $\mathrm{Zn}^{2+}$ coordinating residues D174-O $\delta 1 \ldots$ H157-N $\delta 1$ (3.25 $\AA$ ) and D174-O $\delta 1 \ldots \mathrm{H} 171-\mathrm{N} \varepsilon 1(3.18 \AA$ ) to ligand stability.

The fourth canonical form NiSOD is a hexamer (Fig 9A) found only in cyanobacteria [25] and Streptomyces $[26,27]$ with amino acids ranging from 140-163 and molecular weight between 15-18 KDa. Analysis of available sequences and complete genome sequences revealed that, unicellular Prochlorococcus forms possess only NiSOD, whereas, multicellular filamentous heterocystous and heterotrichous forms lacks this isoform (Table 2). The key for the ubiquity of NiSOD in Prochlorococcus may be due to
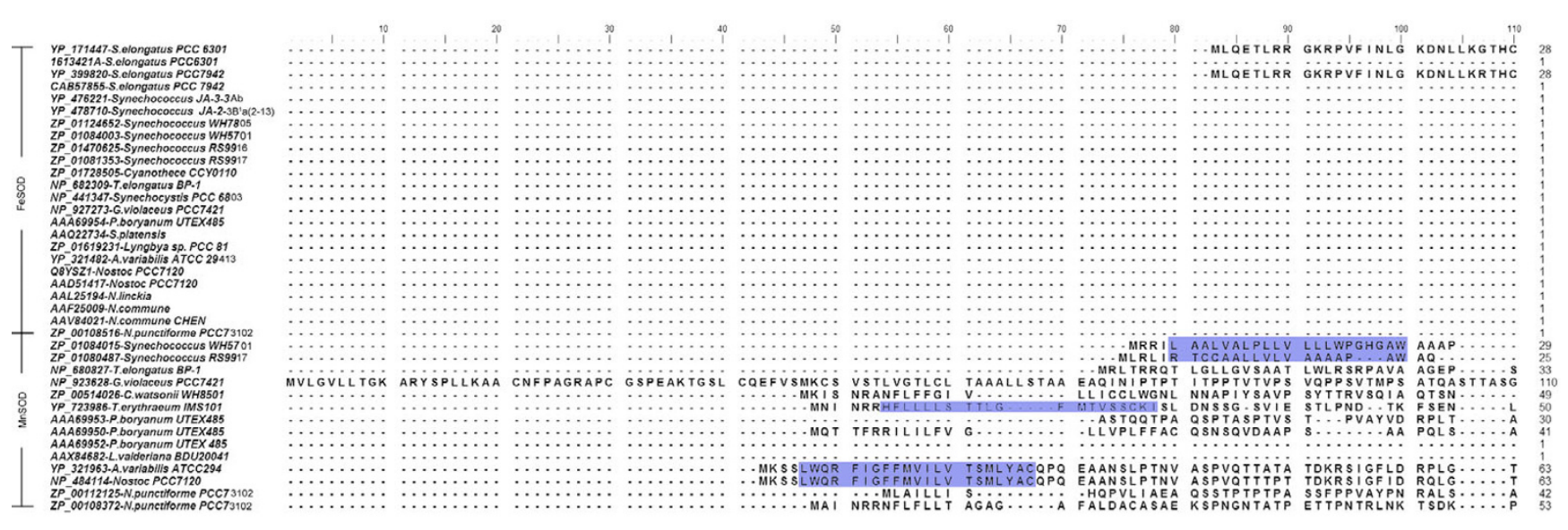

\section{Figure 6}

This figure shows the upper quartile of protein sequence alignment of Fe and MnSODs in cyanobacteria. For full image, please see Additional file I. Transmembrane hydrophobic pocket specific for membrane binding in MnSOD at the N-terminal region is highlighted in violet. 


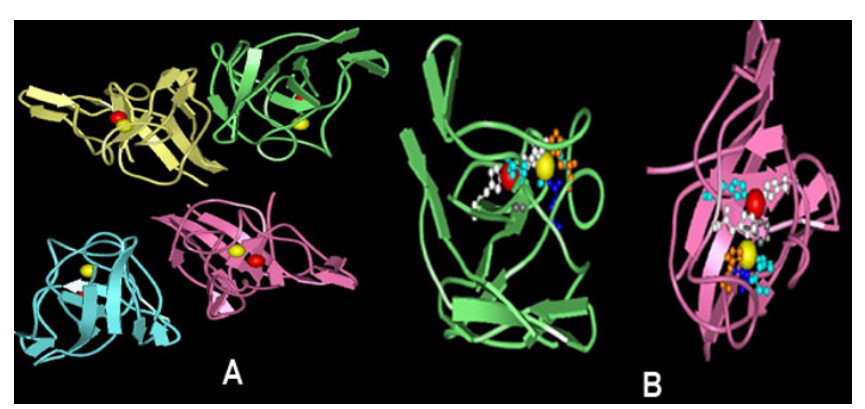

Figure 7

Representative structure of Salmonella typhimurium $\mathrm{Cu} /$ Zn superoxide dismutase. (a) Tetrameric subunits of $\mathrm{Cu} /$ ZnSOD. Chain A coded in green, $B$ in pink, $C$ in yellow and $D$ in cyan. (b) Crystallographic structure of functional S. typhimurium $\mathrm{Cu} / \mathrm{ZnSOD}$ (PDB leqw) subunit is represented to highlight the active site residues in ball and stick mode visualized using WebLab ViewerLite 4.2 software. the primitive photosynthetic machinery and its smallest genome size (between 1669-2434 Kb) by gene rearrangement or loss to maximize the energy economy [28]. The sequence conservation, motif with eleven-residues (HCDGPCVYDPA) in N-terminal region of Ni-hook, along with a nickel containing SOD domain (Pfam:PF09055) forms an unique pattern to identify cyanobacterial NiSOD. Cyanobacterial NiSODs seem to have an assembly of four alpha helices bundle with a short connecting alpha helix, as that of Streptomyces sp. (Fig 9B). The catalytic Ni ion of cyanobacteria is very much analogous to the reported square planar active center with thiolate $(\mathrm{C} 2$, based on $1 \mathrm{t} 6 \mathrm{u})$, backbone nitrogen (H1 and C6) ligands and of square pyramidal Ni (II) with an added axial His ${ }_{1}$ side chain of Streptomyces sp. [29].

\section{Conclusion}

The analysis is based on 64 cyanobacterial SODs available to date in public databases. Among them 2 are described

\begin{tabular}{|c|c|c|c|c|c|c|c|c|c|}
\hline & 10 & & 30 & & 50 & 60 & 70 & m $>>>>2$ & \\
\hline 01472508-Synechococcus RS9916 & $\cdots \cdot 1$ & $\ldots \ldots \ldots$ & $\ldots \ldots$ & $\cdots$. & & VKMTDLO... & 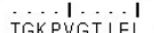 & SONK & I I \\
\hline YP_001224674-SynechococcusWH7805 & 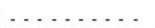 & $\ldots .$. & & & $\ldots . . N T L T$ & VKMNDALSSG & TGENIGE I TV & SETP . . . . & $\ldots$ YGLLFTPH \\
\hline YP_381812-Synechococcus CC9605 & $\ldots \ldots$ & $\ldots .$. & $\ldots .$. & $\ldots \ldots \ldots$ & $\ldots . . \mathrm{QDL} T$ & VKMTDLQ - . & TGKPVGTIEL & SQNK. & . YGVVFIPE \\
\hline ZP_01468043-Synechococcus BL107 & $\ldots \ldots$ & & - MRR- LIAL & MLVVSAVL IW & PGIAKAAAVE & VTLHRISADG & VGE SIGRV SA & RD SD. & . QGLEIIPS \\
\hline YP_376992-Synechococcus CC9902 & $\ldots \ldots$ & $\ldots \ldots$ & - MPR- LVPL & IAL I-LLLCV & PGQASAGSLE & VTLHA & VGDPIGTVKA & HDS & I TPS \\
\hline ZP_01123794-Synechococcus WH7803 & $\ldots \ldots$ & $\ldots \ldots \ldots$ & - MPRL LVQL & VLL I GL I TL T & PGMCDA - L LE & VPLQRIDANG & IGESIGSVTA & QD TD. & . QGLVIYPD \\
\hline ZP_01226581-Synechococcus RCC307 & MSRRAQQMVI & DDV TMKGPGP & NPMRL - L I TI & TCL ICWL IAA & $P .|A K A E P| Q$ & I TMRSINADG & AGDVIGSVTA & KDSD. & . QGLVIFPD \\
\hline YP_730975-Synechococcus CC9311 & $\ldots \ldots \ldots$ & $\ldots \ldots \ldots \ldots$ & - MQP.FLTI & LCL ICWL IAA & P.MANAEPIQ & I TMRS & GSVTA & KDSD & . QG \\
\hline 1BZ0-Escherichia coli & $\ldots \ldots$. & $\ldots \ldots \ldots$ & - MPR - LVPL & IALI-LLLFM & PGQASAGSLE & VTVHSISAEG & VGAPIGSVQA & & - Q QGLVITPT \\
\hline 1EQW-Salmonella typhimurium & $\ldots \ldots$ & $\ldots \ldots$ & - MRLLLSLL & LFL SLLVPSM & P. ALAAEQQ & VWIQRIGGEE & SGEVLGSVMA & RDTS - & . DGLVISPS \\
\hline 1IB5-Photobacterium leiognathi & $\ldots \ldots \ldots$ & $\ldots \ldots$ & - MYR- LGAL & LALC - LALLM & PATVQASTIE & VTINSINTEG & IGESIGT I SA & RDTD. . & - QGLVIIPE \\
\hline EAW38062-Lyngbya PCC8106 & $\ldots \ldots M$ & NIPRK I LSLL & FGLLLMVATV & SCDQIGDSQS & TAEADNTEQI & VAVAEIKGAS & DSNLSGTI TL & TENQPLDTSE & I LPTVEVKAE \\
\hline NP_925116-G.violaceus PCC7412 & . . . . MQKMV & HNAL VDRPGT & RMQGFAVFAG & I FGLLCLLLM & AVPAIDADRW & LQA KI EL KNA & & & \\
\hline NP_924927-G.violaceus PCC7412 & - MVVCRSKVS & GFSLESSGCN & GSEEASMSKH & LFALGAVGWL & LAAPALAGEQ & PAA VSAIKDL & NGQVVGTA TF & $R Q Q P$. & . EGVLVNIQ \\
\hline
\end{tabular}

\begin{tabular}{|c|c|c|c|c|c|c|c|c|c|c|}
\hline & 100 & 110 & 120 & 130 & 140 & 150 & 160 & 170 & 180 & \\
\hline ZP_01472508-Synechococcus RS9916 & LADL TP. GMH & GFH I I $\ldots$ IQNGSC & AS $\cdots 1 \cdots 1$ & $\cdots 1 \cdots 1$ & $\begin{array}{l}\cdots 1 \cdots 1 \\
\cdots \text { SEK-DGKV }\end{array}$ & VLGGAAGGHY & DPEHTNKHGF & $\ldots 1 \ldots$ I & ${ }_{\text {HKGDLPALFV }}$ & 97 \\
\hline YP_001224674-SynechococcusWH7805 & LNGL TP-GIH & GFHVH TNPSC & MP...... & $\ldots \ldots \ldots$ & . GMK-DGKE & VPALMAGGHL & DPEKTGKHLG & PYNDK....G & HLGDLPGLVV & 100 \\
\hline YP_381812-Synechococcus CC9605 & LADL TP - GMH & GFH IHQNGSC & AS. & $\ldots \ldots \ldots$ & - SEK-DGKV & VLGGAAGGHY & DPEHTNKHGF & PYTDD $\ldots . . . N$ & LPALFV & 97 \\
\hline ZP_01468043-Synechococcus BL107 & LSGL TP - GEH & GFHLHANGSC & $\ldots .$. & $\ldots \ldots \ldots$ & - AANADGAM & VAGLAAGGHW & DPDETGEHLG & PFGN ....G & RL WV & 123 \\
\hline YP_376992-Synechococcus CC9902 & LQGL SE-GEH & GFHLHAGDSC & $\cdots \ldots$ & $\ldots \ldots \ldots$ & - ALNAEGVM & VAGLAAKGHW & DPDETNTHLG & PFGN....G & HRGDL SRL WV & 122 \\
\hline ZP_01123794-Synechococcus WH7803 & LAGL TP - GEH & GFHLHSTGSC & EA - & $\ldots \ldots \ldots$ & - GQTAQGTA & I AGLAAGGHW & DPDETGQHLG & PFGN & SRL WV & 122 \\
\hline ZP_01226581-Synechococcus RCC307 & LANL SP - GDH & SNPSC & EA - & $\cdots \ldots \ldots$ & PEGES & AAAGHW & HLG & $\cdots G$ & IV & 144 \\
\hline YP_730975-Synechococcus CC9311 & LVNL TT. GDH & GFHLHSNPSC & EA & $\ldots \ldots \ldots$ & - ALNSEGES & VAGLAAGGHW & DPDNSGTHLG & PFAS & SKL IV & 122 \\
\hline 1BZ̃o-Escherichia coli & LQGL SE-GEH & GFHLHAGDSC & $\mathrm{DA}$ & $\ldots \ldots$ & - AMNGEGEM & VAGLAAKGHW & DPDETNTHLG & PFGN. & HRGDLSKLVV & 122 \\
\hline 1EQW-Salmonella typhimurium & I SGL AA - GAY & GFHLHENGSC & ES & $\ldots \ldots \ldots$ & - GLK-DGVE & VAGLAAGGHW & DPDNTGSHQG & PFGV... & RLVI & 121 \\
\hline 1IB5-Photobacterium leiognathi & SGL SE-GEH & GFHLHAGDQC & AP & $\ldots$ & - QTNSEGAS & I AGLAALGHW & DPDQTNTHLG & PFGN . . & RLVV & 122 \\
\hline EAW38062-Lyngbya PCC8106 & VSGL PPNTKH & GFHIHQTAKC & $E P \ldots \ldots$. & $\ldots \ldots \ldots$ & $\ldots$ DFG. . . . & $\ldots$ AAGGHF & DPGPYGETNP & DANHP. & HMGDLPNL VA & 38 \\
\hline NP_925116-G.violaceus PCC7412 & VQGLLP-GKY & PIHFHSKGKC & VAP. . . . & & $\ldots \ldots$ & - DFRSSRGVF & DTHSLGHKTR & PDGQP . . VP & PAGLLPALIV & 135 \\
\hline NP_924927-G.violaceus PCC7412 & VQGLQP - GKH & AMH IHAVGKC & EPPAFKSAGP & HL GD A KMAP T & SGTPHSHGAK & GA TAL SMNHA & HSAGSMASSI & PHNHGAMHAA & MAGDLPDL VV & 170 \\
\hline
\end{tabular}

\begin{tabular}{|c|c|c|c|c|c|c|c|}
\hline & 190 & & & & & 240 & \\
\hline 01472508-Synechococcus RS9916 & SANGLATNPV & LAPRLT $\ldots$. . & $\cdots$ I $\cdots$ II & AIMIHAGGDN & & & \\
\hline YP_001224674-SynechococcusWH7805 & NADG TATYPL & LAPRLKS... & ...L SELKGH & SLMIHKGGDN & YSDKPA . . PL & GGGARFACG & VIEK-. \\
\hline YP_381812-Synechococcus CC9605 & SANGLATNPV & LAPRL T . . . & ... LKELKGH & AIMIHAGGDN & HSDMPK - AL & GGARVACG & VIQ... \\
\hline ZP_01468043-Synechococcus BL107 & NDDG TTPTSV & VAPRLS $\cdots$ & ... TADLRGK & ALVVHAGGDT & YSDTP...AL & GARIACG & WVGR. - \\
\hline YP_376992-Synechococcus CC9902 & TTTTV & & DLRGR & GGDT &. $\mathrm{PL}$ & & \\
\hline 7803 & TNTSV & & DLKGK & GDT & PL & CG & PDER \\
\hline ZP_01226581-Synect & ISV & $N \ldots$ & LKGR & GDT & क...PL & & VINS. - \\
\hline YP_730975-Synechococcus CC9311 & TSV & $\ldots$ & LKGH & GDT & D... AL & CG & VWN . . \\
\hline 1BZ0-Escherichia coli & TTV & VA & DLRGR & AGGD T & YSDI & RIACG & VG... \\
\hline 1EQW-Salmonella typhimurium & & & $\ldots v$ & GDT &.$P L$ & & GE. . \\
\hline & TTSV & VAPRLK.... & $\cdots A$ & ALVVHAGGDT & YSDTP...PL & IACG & VGS ... \\
\hline PCC8106 & DAQGNAVFTH & RTSRVTLSSG & PLSL FDEDGS & AFIVHIDED. & QGT TGV . . QG & GAGGGRLGCG & IIEKQA \\
\hline _925116-G.violaceus PCC7412 & GAAGTGELNA & & - L LRAHKLH & SLLRPGGSAL & VIHAAHSRQI & CGAVTRTP & VSD . . \\
\hline 924927-G violaceus PCC7412 & GSDGSGKAEI & LNAEVRL TPG & RNFLLQSEGT & ALL IHDVADP & $N Q R \mid A C \ldots G V$ & PNSSPE & AKVNP. \\
\hline
\end{tabular}

\section{Figure 8}

Sequence alignment of cyanobacterial copper zinc superoxide dismutase with bacterial representatives. Alignment was carried out using Clustal W of BioEdit Package (v.7.0.5) [28]. The active site Cu residues are marked as $\star$ and Zn in \#. The signature I residues are highlighted in green and signature 2 in blue. 
Table 2: Annotation of cyanobacterial superoxide dismutases based on sequence and structure conservation.

\begin{tabular}{|c|c|c|c|c|}
\hline Organisms & Accession no & Sequence length & $\begin{array}{c}\text { Type of SOD in } \\
\text { Database }\end{array}$ & $\begin{array}{l}\text { Confirmed isoform } \\
\text { from our study }\end{array}$ \\
\hline Prochlorococcus marinus AS960I & YP 001009883 & 157 & putative $\mathrm{Ni}$ & NiSOD \\
\hline Prochlorococcus marinus CCMPI986 & NP 8934II & 156 & putative $\mathrm{Ni}$ & NiSOD \\
\hline Prochlorococcus marinus CCMPI 375 & NP 875759 & 157 & $\mathrm{Ni}$ & NiSOD \\
\hline Prochlorococcus marinus MIT $930 \mathrm{I}$ & $\underline{\text { YP } 00109170}$ & 157 & putative $\mathrm{Ni}$ & NiSOD \\
\hline Prochlorococcus marinus MIT 9303 & YP 001017980 & 164 & putative $\mathrm{Ni}$ & NiSOD \\
\hline Prochlorococcus marinus MIT $921 \mathrm{I}$ & $\underline{Z P \quad 01004940}$ & 140 & $\mathrm{Ni}$ & NiSOD \\
\hline Prochlorococcus marinus MIT 9312 & YP 397886 & 157 & putative $\mathrm{Ni}$ & NiSOD \\
\hline Prochlorococcus marinus MIT 9313 & NP 894173 & 157 & putative $\mathrm{Ni}$ & NiSOD \\
\hline Prochlorococcus marinus MIT 9515 & $\underline{Y P 001011769}$ & 157 & putative $\mathrm{Ni}$ & NiSOD \\
\hline Prochlorococcus marinus NATLIA & YP 0010155334 & 163 & putative $\mathrm{Ni}$ & NiSOD \\
\hline Prochlorococcus marinus NATL2A & YP 292055 & 163 & putative $\mathrm{Ni}$ & NiSOD \\
\hline Synechococcus sp. WH 8102 & NP 897719 & 157 & putative $\mathrm{Ni}$ & NiSOD \\
\hline \multirow[t]{2}{*}{ Synechococcus sp. BLIO7 } & ZP 01469600 & 157 & putative $\mathrm{Ni}$ & NiSOD \\
\hline & $\underline{Z P} 01468043$ & 198 & putative SOD & Cu/ZnSOD \\
\hline \multirow[t]{2}{*}{ Synechococcus sp. CC9605 } & $\underline{\text { YP } 381196}$ & 157 & putative $\mathrm{Ni}$ & NiSOD \\
\hline & YP 381812 & 178 & SOD precursor (Cu-Zn) & Cu/ZnSOD \\
\hline \multirow[t]{2}{*}{ Synechococcus sp. CC93II } & YP 729969 & 175 & $\mathrm{Cu} / \mathrm{Zn}$ & $\mathrm{Cu} / \mathrm{ZnSOD}$ \\
\hline & $\overline{\text { YP } 730975}$ & 155 & $\mathrm{Ni}$ & NiSOD \\
\hline Synechococcus sp. CC9902 & YP 376992 & 175 & putative SOD & Cu/ZnSOD \\
\hline \multirow[t]{2}{*}{ Crocosphaera watsonii WH 850 I } & ZP 00517273 & 159 & Hypothetical protein & NiSOD \\
\hline & $\underline{Z P \quad 00514026}$ & 254 & SOD & MnSOD \\
\hline \multirow[t]{2}{*}{ Synechococcus elogatus PCC 6301} & YP $17 \mid 447$ & 229 & SOD & FeSOD \\
\hline & $1613421 \mathrm{~A}$ & 202 & SOD & FeSOD \\
\hline \multirow{2}{*}{ Synechococcus elogatus PCC 7942} & YP 399820 & 229 & SOD & FeSOD \\
\hline & CAB57855 & 201 & SOD & FeSOD \\
\hline Synechococcus sp. JA-3-3Ab & YP 476221 & 199 & $\mathrm{Fe}$ & FeSOD \\
\hline Synechococcus sp. JA-2-3B'a(2-13) & $\overline{\text { YP 478710 }}$ & 199 & $\mathrm{Fe}$ & FeSOD \\
\hline \multirow[t]{2}{*}{ Synechococcus sp. WH 7805} & ZP 01124652 & 199 & SOD & FeSOD \\
\hline & $\overline{Z P \quad 01123794}$ & 174 & putative SOD & Cu/ZnSOD \\
\hline \multirow[t]{2}{*}{ Synechococcus sp. WH 570 I } & ZP 01084003 & 199 & SOD & FeSOD \\
\hline & $\underline{Z P \quad 01084015}$ & 231 & $M n$ & MnSOD \\
\hline \multirow[t]{2}{*}{ Synechococcus sp. RS9916 } & $\underline{Z P \quad 01470625}$ & 199 & SOD & FeSOD \\
\hline & ZP 01472508 & 177 & SOD precursor (Cu-Zn) & Cu/ZnSOD \\
\hline \multirow[t]{4}{*}{ Gloeobacter violaceus PCC 742 I } & NP 927273 & 203 & SOD & FeSOD \\
\hline & NP 923628 & 316 & SOD & MnSOD \\
\hline & NP 924927 & 233 & similar to SOD & NA* \\
\hline & NP 925116 & 191 & similar to SOD & NA* \\
\hline \multirow[t]{2}{*}{ Synechococcus sp. RS9917 } & $Z P \quad 01081353$ & 199 & SOD & FeSOD \\
\hline & ZP 01080487 & 229 & SOD & MnSOD \\
\hline Cyanothece sp. CCYOIIO & $\overline{Z P \quad 01728505}$ & 200 & SOD & FeSOD \\
\hline \multirow[t]{2}{*}{ Thermosyncehococcus elongatus BP-I } & NP 682309 & 200 & SOD & FeSOD \\
\hline & NP 680827 & 240 & SOD & MnSOD \\
\hline \multirow[t]{2}{*}{ Lyngbya sp. PCC8I06 } & ZP 0169885 & 201 & SOD & Cu/ZnSOD \\
\hline & ZP 01619231 & 201 & SOD & FeSOD \\
\hline \multirow[t]{2}{*}{ Trichodesmium erythraeum IMSIOI } & YP 723986 & 254 & SOD & MnSOD \\
\hline & YP 720765 & 159 & putative $\mathrm{Ni}$ & NiSOD \\
\hline Synechocystis sp. PCC 6803 & NP 441347 & 199 & $\mathrm{Fe}$ & FeSOD \\
\hline Spirulina platensis & $\overline{\mathrm{AAQ} 22734}$ & 170 & $\mathrm{Fe}$ & FeSOD \\
\hline \multirow[t]{4}{*}{ Plectonema boryanum UTEX 485} & AAA69954 & 199 & $\mathrm{Fe}$ & FeSOD \\
\hline & AAA69953 & 239 & $\begin{array}{l}\text { superoxide dismutase } \\
\text { [Mn] precursor }\end{array}$ & MnSOD \\
\hline & AAA69950 & 248 & & MnSOD \\
\hline & $\overline{\mathrm{AAA} 69952}$ & 206 & & MnSOD \\
\hline Leptolyngbya valderiana BDU2004I & $\mathrm{AAX84682}$ & 144 & $\mathrm{Mn}$ & MnSOD \\
\hline \multirow[t]{3}{*}{ Nostoc punctiforme PCC 73102 } & $\overline{Z P 00108516}$ & 200 & SOD & FeSOD \\
\hline & $Z P \quad 00112125$ & 249 & SOD & MnSOD \\
\hline & ZP 00108372 & 259 & SOD & MnSOD \\
\hline \multirow[t]{2}{*}{ Nostoc sp. PCC 7/ 20} & Q8YSZI & 200 & $\mathrm{Fe}$ & FeSOD \\
\hline & $\underline{A A D 51417}$ & 200 & $\mathrm{Fe}$ & FeSOD \\
\hline
\end{tabular}


Table 2: Annotation of cyanobacterial superoxide dismutases based on sequence and structure conservation. (Continued)

\begin{tabular}{lllll}
\hline \multirow{2}{*}{ Anabaena variabilis ATCC 294/3 } & NP 484114 & 270 & SOD & MnSOD \\
& YP 321482 & 200 & Mn/Fe & FeSOD \\
Nostoc linckia & YP 321963 & 270 & Mn/Fe & MnSOD \\
Nostoc commune & AAL25194 & 200 & SOD & FeSOD \\
Nostoc commune CHEN & AAF25009 & 200 & SOD & FeSOD \\
\hline
\end{tabular}

* Not Assignable (NA)

as $\mathrm{Fe} / \mathrm{Mn}, 4$ as $\mathrm{Cu} / \mathrm{Zn}$ and $\mathrm{Mn}$ precursor, 16 as putative NiSOD, 11 annotated as $\mathrm{Fe}, \mathrm{Mn}$ and $\mathrm{Cu} / \mathrm{Zn}$ isoforms, 29 as possible/putative SOD and 2 as hypothetical proteins.

Thus the present study resolves the incompletely annotated SODs among cyanobacteria (Table 2). Further, 64 cyanobacterial SOD sequences are clearly categorized into 17 NiSOD, $7 \mathrm{Cu} / Z n S O D, 24$ FeSOD and 14 MnSOD genes, 2 non assignable as they require further structural data. The strict metal specificity, precise sequence and structure among the metalloforms led to discriminate Mn and FeSOD (Table 1). The highly homologous Fe and MnSODs shares a metal binding motif DVWEHAYY without any variation, compared to D-X-[WF]-E-H-[STA]-[FY][FY] found in other pro - and eukaryotes.

The whole genome sequences analyses of cyanobacteria reveal that the primitive unicellular Prochlorococcus with simple photosynthetic apparatus possesses only NiSOD. The more evolved middle order forms of cyanobacteria posses a combination of $\mathrm{Fe}$ and $\mathrm{Ni}$ or $\mathrm{Fe}$ and Mn SODs. The most evolved filamentous, heterotrichous and heterocystous forms predominantly have only Fe and Mn metalloforms. However, CuZn also occurs rarely (Table 2).

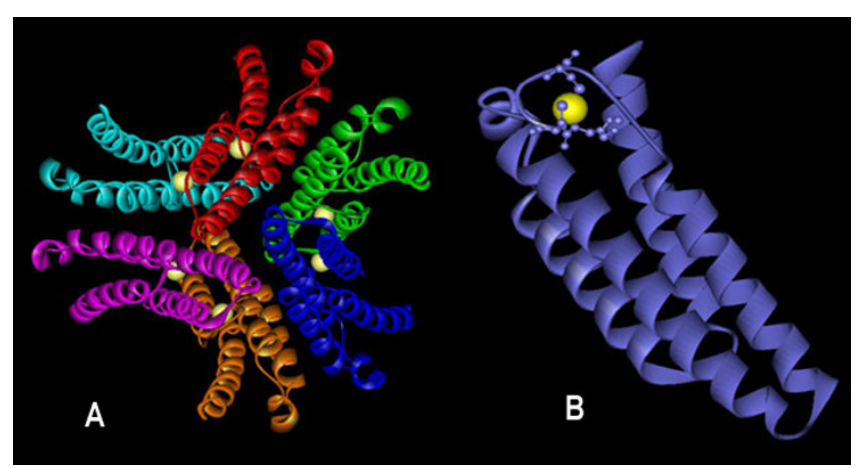

Figure 9

Schematic view of representative NiSOD subunit and hexameric structure of Streptomyces coelicolor [PDB

It6u]. (a) NiSOD biological unit is a hexameric assembly of 4helix bundles (b) NiSOD subunit with metal binding hook labels at the end of helix-I along with the metal shaded in yellow is represented by ball and stick mode as visualized in WebLab ViewerLite 4.2 software.

\section{Methods}

The non-redundant database of protein sequences (National center for Biotechnology Information, NIH, Bethesda) were retrieved using the PHI-BLAST [30] search tool using BLOSOM 62 matrix with gap penalities (Existence - 11 and Extension - 1) with a threshold value of 0.005 and optimal limit for cyanobacteria. The query sequence used were Synechococcus sp. JA-3-3Ab with Expasy-PROSITE pattern D-x-[WF]-E-H-[STA]-[FY]2 for $\mathrm{Fe} / \mathrm{MnSOD}$; Synechococcus sp. RSS9916 with signature 1 [GA]-[IMFAT]-H-[LIVF]-H- $\{\mathrm{S}\}-\mathrm{x}-[\mathrm{GP}]-[S D G]-\mathrm{x}-$

[STAGDE] and signature 2 (G-[GNHD]-[SGA]-[GR]-x-R-x[SGAWRV]-C-X(2)-[IV]) for Cu/ZnSOD. In addition, the individual sequences of all the SOD metalloforms were also manually retrieved from public databases (NCBI, KEGG). Identical sequences from the same organism were removed manually. Intoto, 64 sequences representing 24 complete genomes and individual submissions obtained are listed in Table 2 together with the accession numbers and the organisms. Identification of domains associated with SOD proteins were realized using NCBI Conserved Domain Search and Pfam servers

The secondary structure consensus was carried out using nnPREDICT [31] and JPRED [32] for each protein to refine the multiple sequence alignment. Multiple alignments for cyanobacterial $\mathrm{Fe}$ and MnSODs; and $\mathrm{Cu} /$ ZnSOD sequences were generated using the Clustal W (neighbor-joining) of BioEdit V.7.0.5 [33] program. Default parameter for both the alignments was gap initial penalty- 8 and gap extension penalty of 2 . The alignment was fixed under the PAM40 series protein-weight matrices in both the cases. The sequence alignments were displayed graphically using BIOEDIT package [28] with a threshold of $95 \%$ consensus residue shading.

Representative crystal structures of available cyanobacterial FeSOD (1my6-Thermosynechococcus elongates BP-1) and MnSOD (1gv3-Anabaena sp. PCC7120) with exception for NiSOD (1t6u-Streptomyces coelicolor) and $\mathrm{Cu} /$ ZnSOD (1eqw-Salmonella typhimurium) were retrieved from PDB. The 3D structures were analyzed using SWISSPDB viewer [34] and graphical representations were done with WebLab viewer lite (V.4.2) 


\section{Authors' contributions}

$\mathrm{BP}$ and JP contributed equally in carrying out the sequence analysis studies and participated in the sequence alignment. RTD carried out further confirmation of the results and helped BP in visualization of the structures. TS helped in carrying out the structural comparison. LU and DP participated equally in the study, its design and coordination. GS helped in fine tuning of the manuscript. All authors read and approved the final manuscript written by BP.

\section{Additional material}

\section{Additional file 1}

Excerpts of aminoacid sequences of Fe and MnSOD of cyanobacteria. The proteins are labeled by their accession number with organism source and the metal cofactor specificity. Conserved residues for discrimination of Fe and $\mathrm{Mn}$ metalloforms in cyanobacteria based on multiple alignment using ClustalW of BioEdit Package (v.7.0.5) [28]. The highly conserved metal specific residues are highlighted in red for Fe and green for MnSODs. Transmembrane hydrophobic pocket specific for membrane binding in MnSOD at the N-terminal region is highlighted in violet. Residues involved in outer sphere hydrogen bonding for $\mathrm{Mn}$ is highlighted in cyan and for Fe in orange. For FeSOD, the lysine residues involved in photosynthetic context is shown in pink. The active site residues are marked as I and the dimer residues are represented by *

Click here for file

[http://www.biomedcentral.com/content/supplementary/14712164-8-435-S1.jpeg]

\section{Acknowledgements}

This study was supported by Department of Biotechnology, Government of India, New Delhi. The authors also thank Dr. Kaleel Ahmad, Reader, Jamal Mohammed College, Tiruchirappalli, India for his critical comments and valuable suggestions.

\section{References}

I. McCord JM, Fridovich I: Superoxide dismutase. An enzymic function for erythrocuprein (hemocuprein). J Biol Chem 1969 244:6049-6055.

2. Meier B, Barra D, Bossa F, Calabrese L, Rotilio G: Synthesis of either Fe- or Mn-superoxide dismutase with an apparently identical protein moiety by an anaerobic bacterium dependent on the metal supplied. J Biol Chem 1982, 257:13977-I3980.

3. Amano A, Shizukuishi S, Tamagawa H, Iwakura K, Tsunasawa S, Tsunemitsu A: Characterization of superoxide dismutases purified from either anaerobically maintained or aerated Bacteroides gingivalis. J Bacteriol 1990, I 72:|457-|463.

4. Sugio SB, Hiraoka Y, Yamakura F: Crystal structure of cambialistic superoxide dismutase from Porphyromonas gingivalis. Eur Jiochem 2000, 267:3487-3495.

5. Hiraoka BY, Yamakura F, Sugio S, Nakayama K: A change of the metal-specific activity of a cambialistic superoxide dismutase from Porphyromonas gingivalis by a double mutation of GIn-70 to Gly and Ala-I42 to Gin. Biochem J 2000, 345:345-350.

6. Barghoorn ES: The oldest fossils. Sci Am I97I, 224:30-42

7. Blankenship RE: Molecular evidence for the evolution of photosynthesis. Trends Plant Sci 200I, 6:4-6.

8. Atzenhofer W, Regelsberger G, Jacob U, Peschek G, Furtmuller $P$, Huber R, Obinger C: The 2.0A resolution structure of the catalytic portion of a cyanobacterial membrane-bound manganese superoxide dismutase. J Mol Biol 2002, 32 I:479-489.
9. Herbert SK, Samson G, Fork DC, Laudenbach DE: Characterization of damage to photosystems I and II in a cyanobacterium lacking detectable iron superoxide dismutase activity. Proc Natl Acad Sci USA 1992, 89:871 6-8720.

10. Kim JH, Suh KH: Light-dependent expression of superoxide dismutase from cyanobacterium Synechocystis sp. strain PCC 6803. Arch Microbiol 2005, 183:218-223.

II. Kalib A: Studies on Cyanobacterial tolerance to dessication. Ph.D Dissertation, National Facility for Marine Cyanobacteria, India 2002.

12. Uma Maheshwari R, Kathirvel E, Anand N: Desiccation-induced Changes in Antioxidant Enzymes, Fatty Acids, and Amino Acids in the Cyanobacterium Tolypothrix scytonemoides. World J Microbiol Biotechnol 2007, 23:25I-257.

13. Thomas DJ, Avenson TJ, Thomas JB, Herbert SK: A cyanobacterium lacking iron superoxide dismutase is sensitized to oxidative stress induced with methyl viologen but not sensitized to oxidative stress induced with norflurazon. Plant Physiology 1998, I I 6:1593-1602.

14. Saha SK, Uma L, Subramanian G: Nitrogen stress induced changes in the marine cyanobacterium Oscillatoria willei BDU I 305 I I. FEMS Microbiol Ecol 2003, 45:263-272.

15. Wintjens R, Noel C, May AC, Gerbod D, Dufernez F, Capron M, Viscogliosi E, Rooman M: Specificity and phenetic relationships of iron- and manganese-containing superoxide dismutases on the basis of structure and sequence comparisons. J Biol Chem 2004, 279:9248-9254.

16. Parker WM, Blake CFC: Iron- and manganese-containing superoxide dismutases can be distinguished by analysis of their primary structures. FEB 1988, 229:377-382.

17. Jackson SMJ, Cooper JB: An analysis of structural similarity in the iron and manganese superoxide dismutases based on known structures and sequences. BioMetals 1998, I I:I59- I 73.

18. Edwards RA, Baker HM, Whittaker MM, Jameson GB, Baker EN: Crystal structure of Esherichia coli Manganese superoxide dismutase at 2.I- angstrom resolution. J Biol Inorg Chem 1998, 3:|6I-|7|.

19. Borgstahl GEO, Parge HE, Hickey MJ, Beyer WF Jr, Hallewell RA Tainer JA: The structure of human mitochondrial manganese superoxide dismutase reveals a novel tetrameric interface of two 4-helix bundles. Cell 1992, 71:107-II8.

20. Vance CK, Miller AF: A simple proposal that can explain the inactivity of metal-substituted superoxide dismutases. I Am Chem Soc I 20:46 I-467.

21. Whittaker MM, Whittaker JW: Recombinant superoxide dismutase from a hyperthermophilic archaeon, Pyrobaculum aerophilum. J Biol Inorg Chem 2000, 5:402-408.

22. Regelsberger G, Atzenhofer W, Ruker F, Peschek GA, Jakopitsch C, Paumann Furtmuller PG, Obinger C: Biochemical characterization of a membrane-bound manganese-containing superoxide dismutase from the cyanobacterium Anabaena PCC 7120. Biol Chem 2002, 277:436I5-43622.

23. Wolfe F, Schofield O, Falkowski P: The role and evolution of superoxide dismutase in algae. J Phycol 2005:2-38.

24. Pesce A, Battistoni A, Stroppolo ME, Polizio F, Nardini M, Kroll JS, Langford PR, O'Neill P, Sette M, Desideri A, Bolognesi M: Functional and crystallographic characterization of Salmonella typhimurium $\mathrm{Cu}, \mathrm{Zn}$ superoxide dismutase coded by the sod $\mathrm{C}$ virulence gene. J Mol Biol 2000, 302:465-478.

25. Palenik B, Brahamsha B, Larimer FW, Land M, Hauser L, Chain $P$, Lamerdin J, Regala W, Allen EE, McCarren J, Paulsen I, Dufresne A, Partensky F, Webb EA, Waterbury J: The genome of a motile marine Synechococcus. Nature 2003, 424:1037-1042.

26. Youn HD, Kim EJ, Roe JH, Hah YC, Kang SO: A novel nickel-containing superoxide dismutase from Streptomyces spp. Biochem J 1996, $318: 889-896$

27. Youn HD, Youn H, Lee JW, Yim YI, Lee JK, Hah YC, Kang SO: Unique isozymes of superoxide dismutase in Streptomyces griseus. Arch Biochem Biophys 1996, 334:34I-348.

28. Garcia-Fernandez J, de Marsac N, Diez J: Streamlined regulation and gene loss as adaptive mechanisms in Prochlorococcus for optimized nitrogen utilization in oligotrophic environments. Microbiol Mol Biol Reviews 2004, 68:630-638.

29. Barondeau DP, Kassmann CJ, Bruns CK, Tainer JA, Getzoff ED: Nickel superoxide dismutase structure and mechanism. Biochemistry 2004, 43:8038-8047. 
30. Altschul SF, Madden TL, Schaeffer AA, Zhang J, Zhang Z, Miller W, Lipman DJ: Gapped BLAST and PSI-BLAST : A new generation of protein database search programs. Nucleic Acids Res 1997, 25:3389-3402.

31. Ouali M, King RD: Cascaded multiple classifiers for secondary structure prediction. Protein Sci 2000, 9(6): I |62-II 76.

32. Cuff JA, Barton GJ: Application of multiple sequence alignment profiles to improve protein secondary structure prediction. Proteins 2000, 40:502-5II.

33. Hall TA: BioEdit : a user-friendly biological sequence alignment editor and analysis program for Windows 95/98/NT. Nucl Acids Symp Ser 1999, 41 :95-98.

34. Jones DT: Protein secondary structure prediction based on position-specific scoring matrices. J Mol Biol I 999, 292: 195-202.

35. WebLab ViewerLite software [http://www.accelrys.com/]

Publish with Biomed Central and every scientist can read your work free of charge

"BioMed Central will be the most significant development for disseminating the results of biomedical research in our lifetime. "

Sir Paul Nurse, Cancer Research UK

Your research papers will be:

- available free of charge to the entire biomedical community

- peer reviewed and published immediately upon acceptance

- cited in PubMed and archived on PubMed Central

- yours - you keep the copyright

Submit your manuscript here:

http://www.biomedcentral.com/info/publishing_adv.asp
BiolMedcentral 